\title{
Efek Proses Pendinginan Terhadap Struktur Morfologi Komposit Biodegradable HDPE-Pati Singkong
}

\author{
Nurul Jamilah*, Dasep Rusmana, Roni Sujarwadi, Chandra Liza \\ Balai Teknologi Polimer, Badan Pengkajian dan Penerapan Teknologi (BPPT) \\ Gedung 460 Kawasan PUSPIPTEK, \\ Tangerang Selatan 15314 - Banten, Indonesia \\ *Surel: nurul.jamilah@bppt.go.id
}

\section{INFO ARTIKEL Abstract}

Diterima 10 Januari 2019

Direvisi 22 April 2019

Disetujui 21 Mei 2019

Nomor Artikel 201904

Halaman 21-26

Kata kunci:

Biodegradable

Pati

Proses Pendinginan

Morfologi
The use of an environmentally plastic is commonly for disposable packaging applications. Starch is one of the widely used materials for biodegradable plastics. The processes of biodegradable compound during cooling generally use water, while starch has the properties easily absorb water. This can affect the final product such as packaging. In this work, the effect of adding starch and cooling in the compounding process was observed by morphological structure of biodegradable High Density Polyethylene (HDPE) - cassava starch composite. The cooling process is carried out as a parameter by using water, passed in the water for a minute and cooling with air. A preliminary observation on the addition of starch is done with Melt Flow Rate and Strain at Break. Biodegradable compound by $10 \%$ amount of starch has a value of strain at break: $10.37 \%$ and Melt Flow Rate: $0.258 \mathrm{~g} / 10 \mathrm{~min}$, which is characteristic properties for injection molding process. Furthermore, the cooling process in extrusion was observed the porosity in the biodegradable compound using Scanning Electron Microscope (SEM), the porosity induced by starch because of the nature of starch was easily to absorb water. The results of morphological characterization using SEM in injection molding products, shows the cooling process using water of biodegradable compound was seen the porosity of product. The longer the cooling process with water, the larger the porosity formed. Biodegradable compound with water cooling in a longer time, porosity formed was $5.32 \mu$. And for the compound just go through in the water for a while, had porosity: $2.48 \mu$.

Keywords: Biodegradable, Starch, Cooling process, Morphology

\begin{abstract}
Abstrak
Plastik ramah lingkungan umumnya digunakan untuk aplikasi kemasan sekali pakai, salah satunya adalah penggunaan singkong sebagai bahan plastik biodegradable. Proses pencampuran biodegradable selama pendinginan umumnya menggunakan air, sementara itu pati memiliki sifat mudah menyerap air sehingga memungkinkan terbentuknya porositas pada produk akhir. Pada kegiatan ini dilakukan pembuatan komposit HDPE biodegradable - pati singkong dengan parameter penambahan pati dan proses pendinginan setelah compounding, pengamatan dilakukan melalui struktur morfologi. Parameter proses pendinginan setelah compounding yaitu dengan cara memasukkan sampel ke dalam air selama beberapa menit dan dengan pendinginan udara. Karakterisasi awal dilakukan dengan pengukuran MFR (Melt Flow Rate) dan strain at break. Dari hasil pengujian, campuran biodegradable dengan $10 \%$ pati menghasilkan nilai MFR 0,258 g/10 menit dan strain at break 10,37\%, nilai ini menunjukan karakteristik material polimer untuk proses injection molding. Selanjutnya material setelah proses pendinginan diamati porositas menggunakan alat SEM (Scanning Electron Microscope), porositas terbentuk karena sifat pati yang menyerap air. Hasil morfologi alat SEM menunjukkan adanya porositas dalam produk yang dilakukan proses pendinginan menggunakan air. Pendinganan lebih lama menghasilkan porositas sekitar 5,32 $\mu$ sedangkan
\end{abstract}


pendinginan lebih lambat menghasilkan porositas sekitar $2,48 \mu$. Hal ini dapat disimpulkan bahwa semakin lama proses pendinginan, maka semakin besar porositas yang terbentuk. Sementara proses pendinginan dengan udara tidak membentuk porositas pada komposit HDPE biodegradable - pati singkong.

(C) 2019 JITM

\section{PENDAHULUAN}

Adanya limbah plastik menjadi pemicu para peneliti untuk mengembangkan plastik yang ramah lingkungan. Sifat plastik yang tidak mudah terdegradasi disebabkan karena berat molekulnya yang besar. Pengembangan riset plastik yang mampu terdegradasi (degradable) diawali dengan riset biodegradable plastics. Biodegradable plastics adalah plastik yang terdegradasi dan degradasi plastik ini dapat dipecah oleh metabolisme serta mikroorganisme. Plastik dinyatakan biodegradable apabila plastik tersebut dapat terurai dan rantai atom karbon putus. Rusaknya rantai karbon dapat diproses dan menjadi bagian dari bahan organik sehingga siklus karbon ini merupakan bagian dari ekologi bumi. Selain biodegradabel plastik, ada juga compostable plastic (plastik kompos), yaitu plastik terdegradasi dengan proses biologis selama pengomposan di lingkungan tertentu $[1,2,3]$.

Pengembangan plastik biodegradable saat ini menghadapi beberapa kendala, seperti harga yang mahal, sifat fisiknya yang tidak terlalu bagus dibandingkan dengan plastik berbahan dasar minyak bumi dan proses aplikasinya masih terbatas. Pengembangan degradabel plastik lebih lanjut dilakukan dengan penambahan bahan kimia untuk mempermudah terdegradasi menyebabkan plastik lebih cepat rusak pada kondisi tertentu.

Plastik degradable dapat dibuat dengan cara menambahkan aditif ke dalam plastik berbahan dasar minyak bumi yang akan membuat plastik tersebut rapuh. Beberapa metode plastik terdegradasi, diantaranya melalui paparan sinar matahari selama periode tertentu yang disebut sebagai plastik photodegradable, melalui oksidasi dan panas yang disebut sebagai plastik oxo-degradable [4]. Proses degradasi ini terjadi karena adanya pengaruh fragmentasi mikroplastik yang terus menerus mengecil dan terasimilasi dengan mikroorganisme. Akan tetapi, hal ini masih diperlukan penelitian lebih lanjut untuk memverifikasi berapa lama waktu yang dibutuhkan. Keberadaan fragmentasi plastik ini dapat menjadi penyebab tercemarnya lautan [5]. Karena itu, penelitian menggunakan plastik berbahan dasar alam masih terus dikembangkan.

Pati merupakan salah satu bahan yang paling banyak digunakan untuk plastik biodegradable [6, 7]. Proses compounding (pencampuran) biodegradable selama pendinginan umumnya menggunakan air, sedangkan pati ini memiliki sifat mudah menyerap air yang berpengaruh terhadap produk akhir seperti pengemas $[8,9]$.

Dalam penelitian ini, efek penambahan pati dan pendinginan setelah proses compounding diamati melalui struktur morfologi dari komposit biodegradable High Density Polyethylene (HDPE) - pati singkong. Ada dua cara proses pendinginan, yaitu proses pendinginan menggunakan air dan dengan pendinginan udara.

\section{METODE PERCOBAAN}

Bahan yang digunakan dalam penelitian ini antara lain Glycerol Monostearate (GMS) diperoleh dari perusahaan lokal sebagai plastisiser pati. Pati singkong dari pasar tradisional sebagai material biodegradable dan High Density Polyethylene $(H D P E)$ tipe 5502 GA dari SIDPEC, jenis kopolimer dengan berat molekul sedang. Polyethylene graft maleic anhydride (PEgMA) dari Sigma Aldrich digunakan sebagai compatibilizer antara pati dan HDPE.

Untuk proses compounding digunakan Twin Screw Extruder, Collin ZK 25E. Karakterisasi laju alir lelehan, menggunakan Melt Flow Rate (MFR), CEAST. Universal Testing Machine (UTM), Shimadzu AGS $10 \mathrm{kN}$ digunakan untuk karakterisasi strain at break. Karakterisasi Morfologi struktur komposit dilakukan menggunakan Scanning Electron Microscope (SEM), JEOL JSM-6510LA. Pengukuran dilakukan di tiga area yang berbeda dengan perbesaran 500x (morfologi permukaan sampel), 1000x (morfologi cross section/bagian melintang sampel) dan 2000x (morfologi sampel pendinginan dengan air dan dengan udara). Parameter pengujian menggunakan accelerated voltage $20 \mathrm{kV}$ dan tampilan menggunakan SEI (Secondary Electron Image)

Sampel terlebih dahulu dipreparasi dengan cara mengeringkan pati yang dicampur dengan GMS selama 24 jam dalam oven pada suhu $60^{\circ} \mathrm{C}$. Selanjutnya, hasil pengeringan dicampur dengan compatibilizer dan resin HDPE menggunakan pencampuran manual sebelum diekstrusi menggunakan twin screw extruder.

Preparasi HDPE biodegradable dan senyawa pati dibuat dalam tiga formulasi (Tabel 1). 
Tabel 1. Nomenklatur sampel biodegradable.

Table 2.Karakteristik uji tarik dan MFR komposit biodegradable.

\begin{tabular}{|c|c|c|c|c|c|c|c|c|c|c|}
\hline No & Nomenklatur & HDPE & Pati/GMS & $\begin{array}{l}\text { Compatibilizer } \\
\text { PEgMA }\end{array}$ & No & Sampel & $\begin{array}{l}\text { Uji Tarik } \\
\text { (MPa) }\end{array}$ & $\begin{array}{l}\text { Modulus } \\
\text { (Gpa) }\end{array}$ & $\begin{array}{c}\text { Strain } \\
\text { at break } \\
(\%)\end{array}$ & $\begin{array}{l}\text { MFR } \\
\text { (gr/10 } \\
\text { menit) }\end{array}$ \\
\hline 1 & HDPE/Pati 20 & $74 \%$ & $20 \%$ & $6 \%$ & 1 & HDPE/Pati 20 & 40.80 & 1.40 & 5.90 & 0.240 \\
\hline 2 & HDPE/Pati 15 & $79 \%$ & $15 \%$ & $6 \%$ & 2 & HDPE/Pati 15 & 41.96 & 1.36 & 6.32 & 0.243 \\
\hline 3 & HDPE/Pati 10 & $84 \%$ & $10 \%$ & $6 \%$ & 3 & HDPE/Pati10 & 36.55 & 1.26 & 10.37 & 0.258 \\
\hline & Proses $c$ & d & 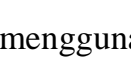 & & 4 & HDPE & 41.22 & 1.33 & 12.29 & 0.249 \\
\hline
\end{tabular}
proses pendinginan menggunakan air dengan cara memasukkan sampel ke dalam air (Gambar 1) dan dengan pendinginan udara (Gambar 2). Parameter kondisi operasi: temperatur $40-195^{\circ} \mathrm{C}$ dan screw speed 50 rpm. Selanjutnya, hasil compounding dikarakterisasi menggunakan UTM, MFR dan SEM, untuk menentukan formulasi yang akan digunakan dalam pembuatan prototipe. Kemudian dilakukan pembuatan prototipe menggunakan injection molding, karakterisasi morfologi prototipe diobservasi menggunakan SEM.

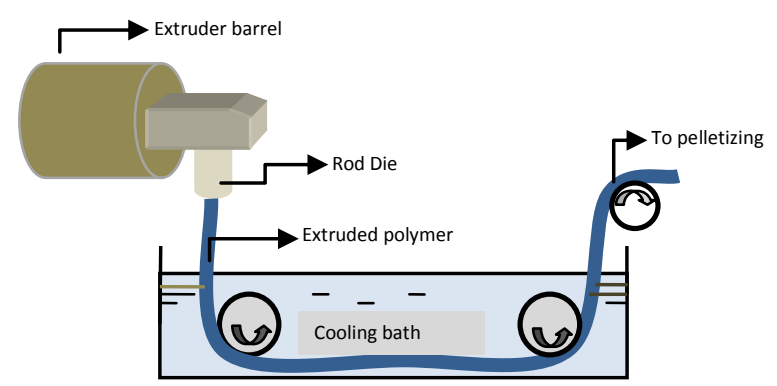

Gambar 1. Proses pendinginan dengan air.

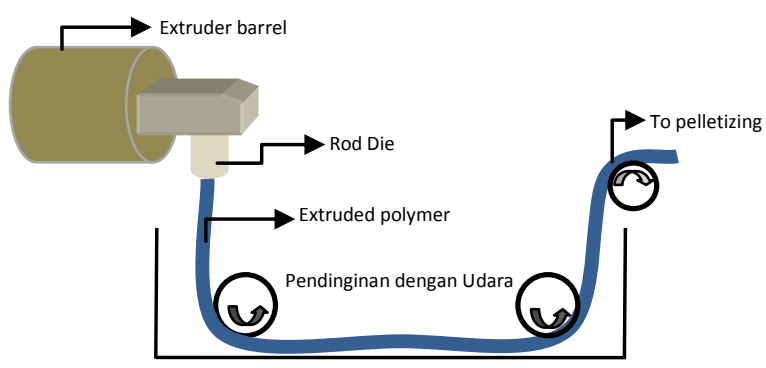

Gambar 2. Proses pendinginan dengan udara.

\section{HASIL DAN PEMBAHASAN}

Tabel 2 memperlihatkan bahwa nilai strains at break HDPE/Pati 10 mendekati nilai HDPE murni. Selain itu, gambar morfologi potongan melintang sampel (Gambar 3 dan 4) memperlihatkan campuran pati dan HDPE homogen pada sampel HDPE/Pati 10. Pada penambahan starch dalam jumlah sedikit (10 \%wt), menghasilkan dispersi yang baik [10]. Berdasarkan kedua hal tersebut, HDPE/Pati 10 dapat digunakan untuk proses selanjutnya.

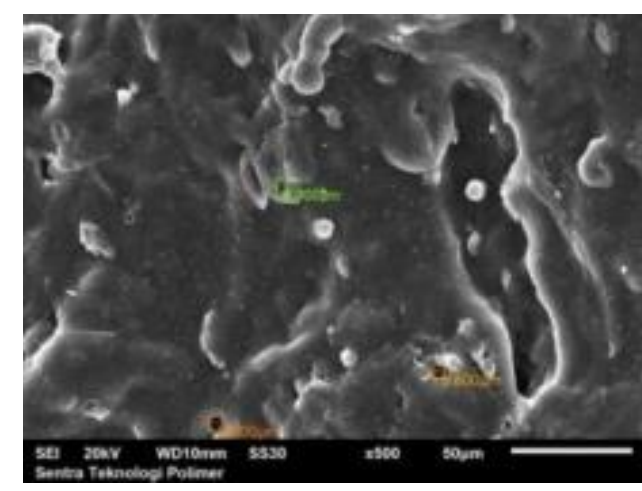

A

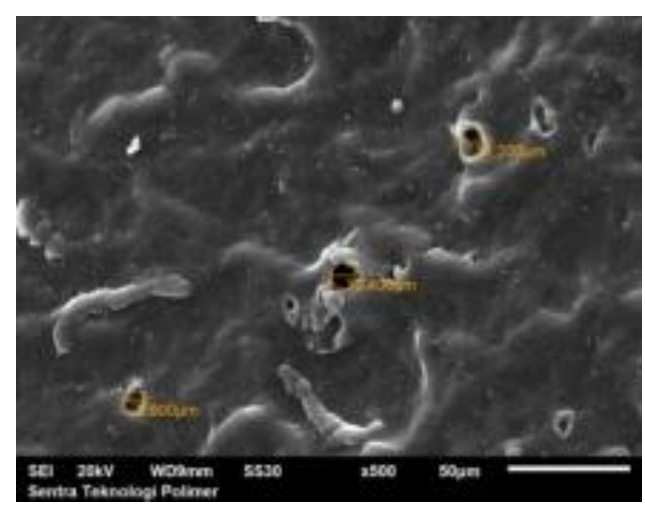

B

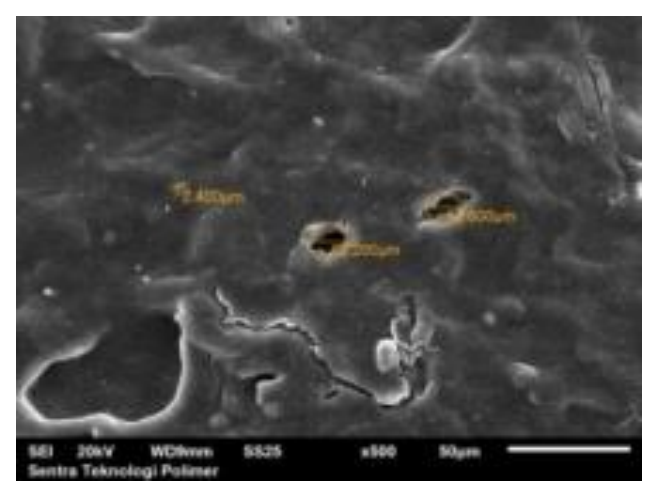

C

Gambar 3. Morfologi permukaan sampel. a. HDPE/Pati 20, b. HDPE/Pati 15, dan c. HDPE/Pati 10. 


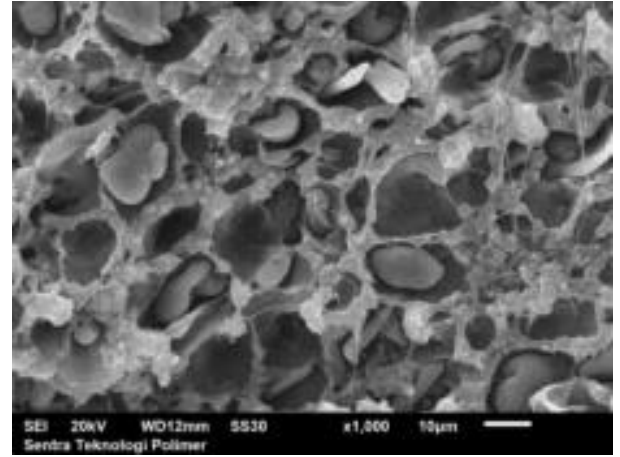

A

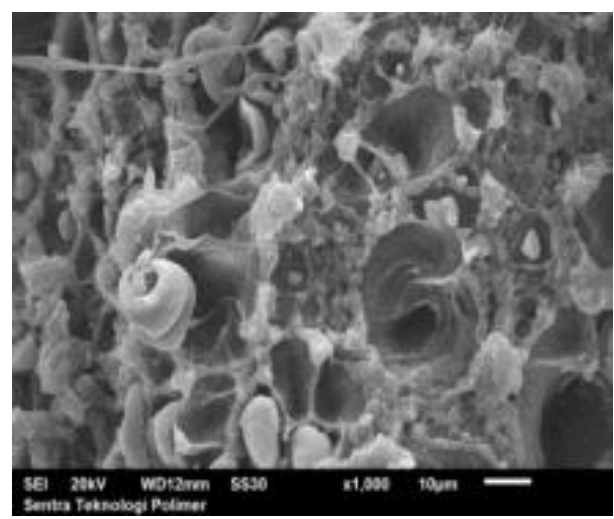

B

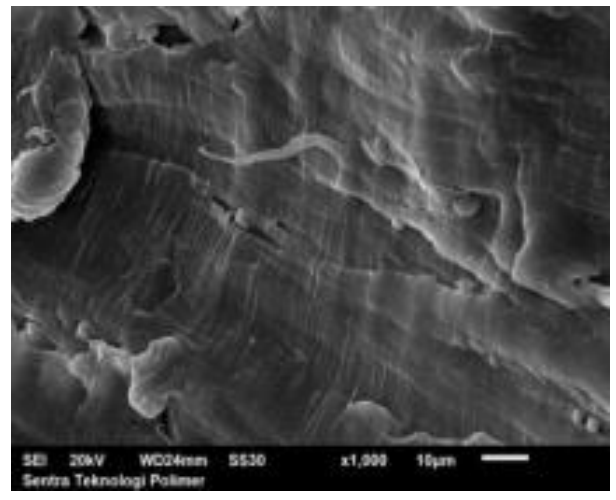

$\mathrm{C}$

Gambar 4. Morfologi potongan melintang sampel a. HDPE/Pati 20, b. HDPE/Pati 15 dan c. HDPE/Pati 10

Pembuatan pelet komposit HDPE/Pati 10 dilakukan dengan proses ekstrusi, dengan dua tipe proses pendinginan, yaitu pendinginan dengan air dan dengan udara (Gambar 1 dan 2). Selanjutnya, dibuat prototipe sampel menggunakan injection molding. Perbedaan terlihat dari permukaan prototipe sampel antara pendinginan dengan air dan dengan udara. Dalam hal ini, sampel pendinginan dengan air terlihat silver strike - lebih mengkilap daripada sampel pendinginan dengan udara. Hal ini mengindikasikan bahwa pelet masih mengandung air [11].
Analisa selanjutnya adalah pengukuran pori atau lubang yang terbentuk di tiga area berbeda menggunakan SEM (Tabel 3). Hasil analisa SEM diperlihatkan dalam Gambar 5 dan 6.

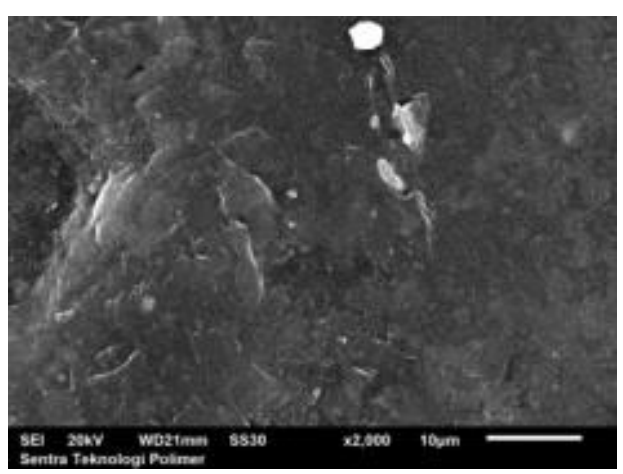

A

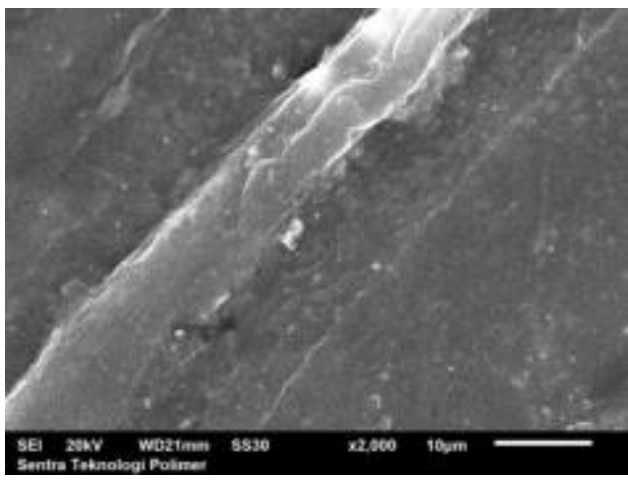

B

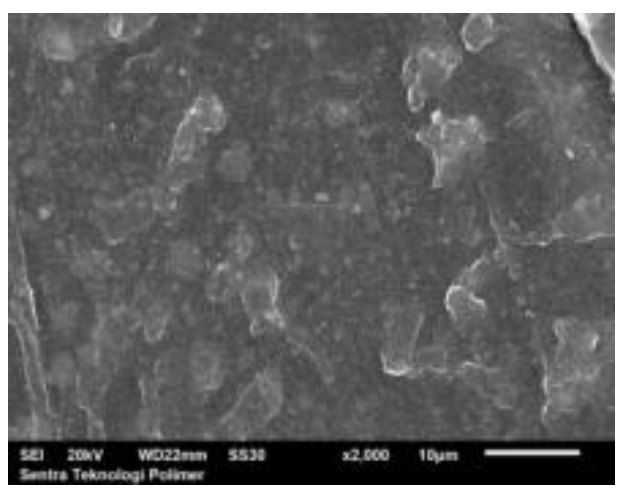

$\mathrm{C}$

Gambar 5. Morfologi sampel pendinginan dengan udara. Perbesaran 2000x: a. Area 1; b. Area 2; and c. Area 3 


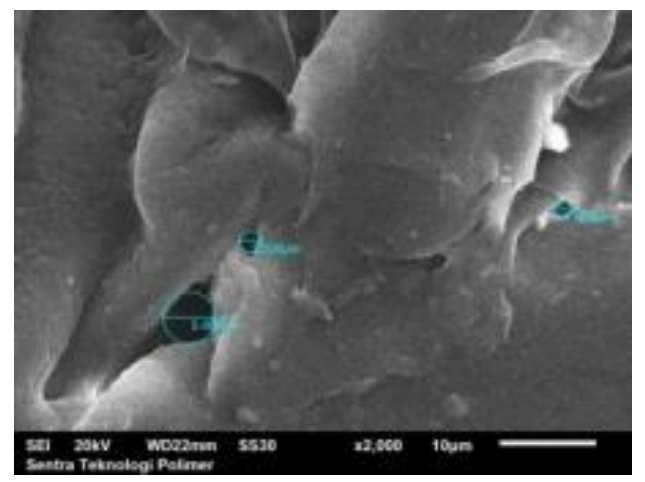

A

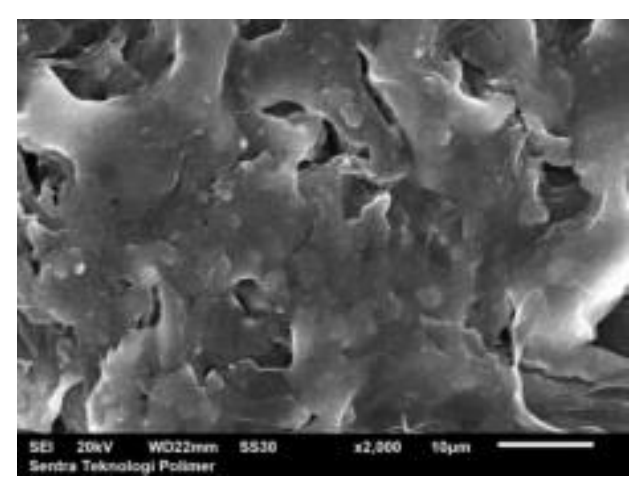

B

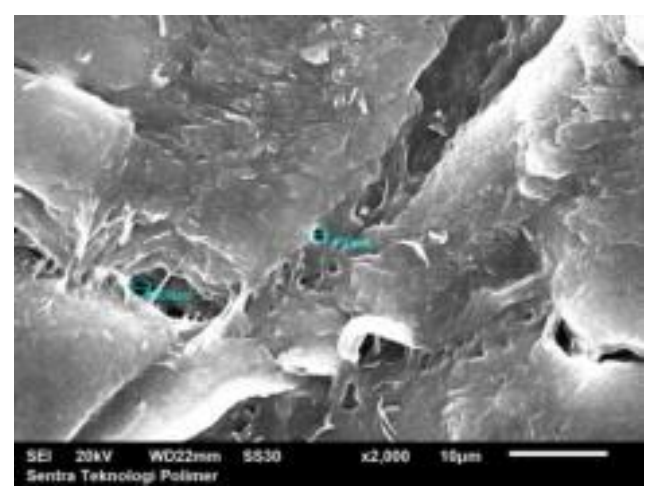

C

Gambar 6. Morfologi sampel pendinginan dengan air. Perbesaran 2000x: a. Area 1; b. Area 2; and c. Area 3.

\begin{tabular}{ccc}
\multicolumn{3}{c}{ Tabel 3. Pengukuran porositas sampel pendinginan dengan air } \\
\hline No & Pori & Diameter $(\mu \mathrm{m})$ \\
\hline 1 & Pori 1 & 5,40 \\
2 & Pori 2 & 2,20 \\
3 & Pori 3 & 1,80 \\
4 & Pori 4 & 1,60 \\
5 & Pori 5 & 1,40 \\
& Rata-Rata & $\mathbf{2 , 4 8}$ \\
\hline
\end{tabular}

Dari Gambar 5 terlihat bahwa tiga area sampel yang berbeda pada sampel pendinginan dengan udara tidak tampak pori / lubang. Sementara itu, sampel pendinginan dengan air terlihat banyak pori/lubang (Gambar 6) dengan ukuran diameter di Tabel 3.

\section{KESIMPULAN}

Hasil karakterisasi menggunakan SEM menunjukkan bahwa proses pendinginan dengan udara tidak terbentuk pori-pori dalam produk. Berbeda halnya dengan sampel pendinginan dengan air, poripori masih terbentuk dalam sampel walaupun ukurannya kecil sekitar 2,48 $\mu \mathrm{m}$. Hal ini disebabkan karena kemungkinan air terperangkap dalam compound dan menghasilkan pori. Pori-pori ini menyebabkan inisiasi pecahnya produk apabila produk dilakukan proses injection blow molding. Demikian juga air yang terjebak dalam kompon membuat tampilan permukaan sampel terlihat lebih mengkilat (silver streak).

\section{UCAPAN TERIMAKASIH}

Terima kasih kami ucapkan kepada Balai Teknologi Polimer yang telah memberikan kesempatan untuk melakukan kegiatan pembuatan komposit biodegradabel dan pelaksanaan karakterisasi.

\section{DAFTAR PUSTAKA}

[1] Sam Deconinck. 2013. "Benefit and Challenges of Bio and Oxo Degradable Plastic", Plastic Europe AISBL.

[2] Andersen, J., A. Boldrin, J. Samuelsson, T. H. Christensen, and C. Scheutz, 2010. "Quantification of Greenhouse Gas Emissions from Windrow Composting of Garden Waste". J. Environ. Qual., 39:713-724.

[3] Galen Killam, 2010. "Plastic Biodegradation in Landfill” Ecologic-LLC.

[4] Michael Pitzl, 2010. "Renewable vs Biodegradable. New Material for Packaging Technology", Austrian Research Institute for Chemistry and Technology-OFI, Cropack.

[5]. Giuseppe Andrea de Lucia. (2018, Augustus). "Sea Water Contamination in the Vicinity of the Italian Minor Islands Caused by Microplastic Pollution", MDPI. https://www.mdpi.com/20734441/10/8/1108/pdf (diunduh 25 Januari 2019).

[6] Elmi Kamsiati, Heny Herawati dan Endang Yuli Purwani. 2017. "Potensi Pengembangan Plastik Biodegradable Berbasis Pati Sagu dan Ubi Kayu 
di Indonesia", Jurnal Litbang Pertanian, vol. 36 No.2:67- 76. https://media.neliti.com/.../229236potensi-pengembangan-plastik-biodegradabb00d. (diunduh 24 Januari 2019).

[7] Afiifah Radhiyatullah, Novita Indriani, M. Hendra S. Ginting. 2015. "Pengaruh Berat Pati dan Volume Plasticizer Gliserol terhadap Karakteristik Film Bioplastik Pati Kentang”, Jurnal Teknik Kimia USU, Vol.4, No.3, https://jurnal.usu.ac.id/index.php/jtk/article/down load/10844/4842 (diunduh 24 Januari 2019).

[8] Hongsheng Liua, Fengwei Xiea, Long Yu, Ling Chena, Lin Li, 2009. "Thermal processing of starch-based polymers", Progress in Polymer Science, 34: 1348 - 1368.

[9] F. J. Aranda-García, R. González-Núñez, C. F. Jasso-Gastinel, and E. Mendizábal. 2015. "Water Absorption and Thermomechanical Characterization of Extruded Starch/Poly(lactic acid)/Agave Bagasse Fiber Bioplastic Composites", International Journal of Polymer Science, Volume 2015, Article ID 343294.

[10] Hale Berber Yamak. 2016. "Thermal,Mechanical and Water Resistance Properties of LDPE/Starch Bio-Based Polymer Blends for Food Packing Applications. JOTCSA, Vol.3(3): 637-656.

[11] Jozef BÍLIK, Antonín NÁPLAVA, Martin KUSÝ, Miroslav KOŠÍK, Lukáš LIKAVČAN. 2014. "Silver Streaks on Surface of Injected Thermoplastic Parts", Research Papers Faculty of Materials Science and Technology in Trnava Slovak University of Technology in Bratislava, Vol. 22, No 34. 